\title{
NEGRITUDE(S) E IDENTIDADE(S) NA HIPERMIIDIA: A UBIQUIDADE DO SER E DA PALAVRA NEGRO NA CONTEMPORANEIDADE
}

André Freitas Miranda

\section{Considerações iniciais}

As identidades dos sujeitos se constroem nas relações interpessoais, culturais e sociais estabelecidas entre eles e com o meio social onde vivem. Isso é um fato. Mas parece que, quando se fala sobre o povo preto, suas identidades são reduzidas a estereótipos que, muitas vezes, pouco se aproximam daquilo que realmente são e, pior, tendem a construir e a reproduzir um arquétipo único e homogêneo de pessoa negra, o qual, não se pode negar, quase sempre reflete um racismo estrutural ainda bastante presente em nossa sociedade e resultado de anos de escravidão. 
De modo geral, muito tem se falado sobre as novas relações que têm sido estabelecidas e transformadas nas sociedades contemporânea, e, por vezes, busca-se delimitar a identidade dos contornos do homem da contemporaneidade. No entanto, quando se ampliam as lentes para esse assunto, percebemos que o povo preto sofre ainda mais homogeneização, sendo-lhe renegadas e deslegitimadas suas individualidades, subjetividades e vivências únicas como sujeitos que, claro, fazem parte de uma cultura e são afetados e construídos por ela, mas, igualmente óbvio, são únicos em suas individualidades. Ainda assim, colocar a construção da(s) identidade(s) do povo preto no centro dessas discussões parece encontrar dificuldades para responder a questões como "O que é negritude?”, “O que é ser preto/negro?”, “Quem faz parte do povo preto/negro?", "Quais os traços de suas identidades e como estas se constroem?". Obviamente, não se pode responder de imediato a perguntas como estas - tão pouco é nosso objetivo principal provavelmente, nunca se consiga, conquanto não exclua a possibilidade - e necessidade - de se pensar em como os discursos estereotipantes têm influenciado na construção e desconstrução das [imagens de] identidades do povo preto e, mais ainda, como tais discursos têm reproduzido negativamente uma imagem única de um representante universal de toda a população negra, em especial a do Brasil.

Hoje, dificilmente conseguiríamos traçar discussões sobre identidades contemporâneas sem se levar em conta as relações de poder e a grande influência das hipermídias e das redes sociais na construção desses traços que caracterizam o sujeito; inclusive do povo preto que, como qualquer outro, faz parte e atua na sociedade, não está alheio a ela nem a suas mudanças. Anthony Giddens (2007), em "O mundo da era da globalização", já destacava que as coisas mais simples que as pessoas fazem em seu dia a dia podem, 
muitas vezes, ser reflexos de uma globalização que reorganizou as relações estabelecidas socialmente, transformando-as. Stuart Hall (2006), por sua vez, em "A identidade cultural na pós-modernidade", afirmava que as identidades modernas estão sendo descentradas, deslocadas ou fragmentadas, não sendo possível definir, $a$ priori, os traços de identidade do sujeito, seus lugares e seu futuro, através da criação homogênea de um grupo de indivíduos, como o que tem acontecido com a população negra.

Bakhtin/Voloshinov (2009) afirmam que o homem é um sujeito de linguagem, sígnio, ideológico, social, e que só se constitui como tal na interação e relação com o outro. Nesse sentido, entendemos que as identidades dos sujeitos se constroem nas relações interpessoais - e sociais - estabelecidas entre eles e com o meio social onde vivem, num processo de alteridade constitutivo. Importa, então, para a discussão que pretendemos, pensar não os lugares, mas as possibilidades inúmeras de lugares que o povo preto pode e deve ocupar, a partir de escolhas do próprio sujeito negro que, fazendo parte de um grupo diverso e heterogêneo, enxerga e entende sua individualidade e subjetividade, podendo estar em diversos lugares e espaços sociais e sendo o sujeito, indivíduo, cidadão negro/preto ${ }^{1}$ que se enxerga ser, sem desprezar a história de luta e resistência de seu povo.

É nesse sentido, outrossim, que procuraremos discutir a ubiquidade do Ser e de ser negro e sua característica própria de ser e estar em todo e qualquer lugar/espaço social: na música pop, funk, MPB ou hip-hop, como Ludmilla, Liniker, Seu Jorge e Emicida; nos poemas e artes cênicas e dramáticas, como Elisa Lucinda, Zezé Motta, Douglas Silva Samarao, Ícaro Silva, Milton Gonçalves e Conceição Evaristo; na academia, como Djamila Ri-

1 Os termos negro e preto são, para este estudo, equivalentes e se alternarão durante as discussões. 
beiro e Lélia Gonzales; na política, como Marielle Franco, David Miranda, Erika Hilton, Joaquim Barbosa; e em tantos outros espaços de ação, voz e vez.

Nosso estudo se embasa em discussões pertinentes à Análise do Discurso de linha francesa (AD), valendo-se, principalmente, das noções de ethos e cenografia discutidas por Maingueneau (2010; 2015), em diálogo com a perspectiva da filosofia da linguagem de Bakhtin (2009; 2010; 2011) e os estudos culturais de Stuart Hall (2006) e Munanga (1988; 2000), para entender como o discurso de diferentes pessoas negras constrói diferentes ethe de pessoas negras/pretas. Destacamos que nossos diálogos, de caráter teórico-prático, não delimitarão suas análises a um corpus fechado, mas farão observações acerca de duas amostras, entendidas, aqui, como cenografias, de falas de personalidades negras, como exemplos da grande diversidade que compõe o povo preto nos mais diversos campos de atuação mediados pela linguagem, em especial, a hipermídia: a saber: postagens da cantora Ludmilla na rede social Twitter e trechos da letra da música "AmarElo", interpretada por Emicida, Pabllo Vittar e Majur, acompanhados de duas imagens do videoclipe da canção.

\section{Ethos e cenografia: a identidade do sujeito negro numa construção contínua}

Reconhecer-se e colocar-se como negro, numa sociedade racista como a brasileira, parece que ainda é um processo que boa parte da população negra do país passa, e a dificuldade de aceitar-se - e mais, orgulhar-se - como pertencente a esse grupo tem raízes em muitas esferas: social, religiosa, cultural, estético-ética. 
Não é difícil encontrar pessoas que tenham dificuldades de dizer “Sou negro(a)!", parece soar mais fácil e aceitável socialmente enxergar-se como moreno(a) ou moreninho(a), pardo(a). Provavelmente isso ocorra pelo fato de que quase tudo que é associado às palavras negro e preto, e, óbvio, à cultura dessa população, parece padecer, em algum grau, de conotações negativas. A problemática fica ainda mais evidente, quando levamos a questão para as mídias, principalmente às de grande massa, como a TV aberta e as redes sociais, que muitas vezes, na tentativa de alcançarem um bom engajamento, pormenorizam a questão da representatividade e identidade do povo preto e reduzem ser negro a um comportamento homogeneizado e esvaziado.

A questão da identidade do povo preto é um desafio que tem raízes bastante profundas, a ponto de o sujeito negro ser estereotipado a um único perfil, seja na música, na dança, nos gostos em geral e, claro, seus discursos. Como se a compreensão da negritude de um indivíduo negro fosse a de todos os outros. A negritude nasce, segundo Munanga (1988), num contexto socio-histórico bem específico, ainda na época da colonização do continente africano pela Europa, a partir do momento em que o negro percebe que não é, apenas, diferente, mas é visto e tratado como diferente; uma raça diferente, uma subespécie humana.

Mas este é um conceito inicial. Para Césarie (apud MUNANGA, 2000): negritude é o simples reconhecimento do fato de ser negro e tem a ver com assumir com orgulho sua Identidade negra como algo histórico e cultural; manter uma fidelidade à causa através de uma ligação com a terra-mãe, África; e ter solidariedade com os demais negros, reconhecendo-se como pertencente a este grupo. Para o senegalês Léopold Sedar Senghor, negritude 
é o conjunto dos valores culturais do mundo negro, exprimidos na vida e obras: "é a proclamação-celebração sobre todos os tons de identidade, da personalidade coletiva, visando o retorno às raízes do negro como condição de um futuro diferente da redução presente" (SENGHOR apud MUNANGA, 1988, p. 25). Os autores defendem que o negro deve ter orgulho de ser quem é, reconhecer o desprezo que recebe, ressignificando-o como "uma operação para desintoxicação semântica e de constituição de um novo lugar de inteligibilidade da relação consigo, com os outros e com o mundo" e, a nosso ver, de alteridade: é preciso ter uma compreensão da história, de si e de seu lugar no mundo moderno e dos outros indivíduos, fazendo sua própria história como sujeito dela.

Os europeus, na busca de justificarem sua atitude oportunista,

[...] além da força como meio para manter esse violento equilibrio, recorreu-se oportunamente aos estereótipos e preconceitos através de uma produção discursiva. Aí, toda e qualquer diferença entre colonizador e colonizado foi interpretada em termos de superioridade e inferioridade. Tratava-se de um discurso monopolista, da razão, da virtude, da verdade, do ser etc. (MUNANGA, 1988, p. 8).

Foi dada uma licença, inclusive pela religião e pela ciência, com valor de verdade, divina, científica e absoluta, para escravizar pessoas; pessoas essas tratadas como sem história, sem passado, sem humanidade. Essa licença, para além da força bruta acontecia também através do e pelo discurso, e, como mostram a história e os fatos atuais, tal permissividade ainda não foi superada, tendo que o negro, de diferentes maneiras, como na hashtag \#blacklives- 
matter $^{2}$, dizer redundante, mas necessariamente, que vidas negras importam.

Manunga (2000) lamenta que nossa sociedade carregue um saldo negativo de um racismo que vem do fim do século XVIII aos meados do século XIX, e que, em contrapartida ao fato de "a consciência política reivindicativa das vítimas do racismo nas sociedades contemporâneas está cada vez mais crescente, o que comprova que as práticas racistas ainda não recuaram”, surgiu uma “[...] nova forma de racismo: o racismo construído com base nas diferenças culturais e identitárias", (p. 27), que gera um grande paradoxo:

Se por um lado, os movimentos negros exigem o reconhecimento público de sua identidade para a construção de uma nova imagem positiva que possa lhe devolver, entre outro, a sua autoestima rasgada pela alienação racial, os partidos e movimentos de extrema direita na Europa, reivindicam o mesmo respeito à cultura "ocidental" local como pretexto para viver separados dos imigrantes árabes, africanos e outros dos países não ocidentais ( $M U$ NANGA, 2000, p. 27-28).

Todavia, este movimento paradoxo não é exclusivo dos países europeus, o tópico "todas as vidas importam" repercutiu no Brasil, nos últimos tempos, como antagonista a "vidas negras importam"; ou mesmo quando se cria um paralelo entre o "Dia da

2 Vidas Negras Importam. Trata-se de uma organização que surgiu em 2013, fundada pelas ativistas Alicia Garza, Patrisse Cullors e Opal Tometi. Mas se popularizou no Brasil e no mundo como a hastag \#blacklivesmatter, após a morte de George Floyd por um policial branco. Conf. Em: https://www.uol.com.br/universa/noticias/redacao/2020/06/03/ black-lives-matter-conheca-o-movimento-fundado-por-tres-mulheres. htm. 
consciência Negra" e um fictício "Dia da consciência humana". O discurso racista insiste em descreditar a luta em busca de uma sociedade, de fato, igualitária e combatente ao racismo estrutural, que tanto aflige o povo preto e perpetua uma desigualdade histórica, sem a mínima preocupação de reparação com essa população.

Contudo,

É a partir da tomada de consciência dessas culturas de resistência que se constroem as identidades culturais enquanto processos e jamais produtos acabados. São essas identidades plurais que evocam as calorosas discussões sobre a identidade nacional e a introdução do multiculturalismo numa educação-cidadã, etc. (MUNANGA, 2000, p. 32).

É preciso ter claro que os negros não produzem cultura e identidades negras como uma laranjeira produz laranja: "esta identidade política é uma identidade unificadora em busca de propostas transformadoras da realidade do negro do Brasil" (Ibid., p. 33), o que não significa dizer que exista um estereótipo de negro que reflita as subjetividades e individualidades de toda a população negra, pois

Embora a busca pela identidade diante da assimilação colonial pudesse conciliar todos os negros, não era [não é] fácil, no entanto, realizar um acordo sobre questões de opção e orientação política, escolha do modelo de desenvolvimento e do tipo de relação a se manter com as antigas metrópoles e os grandes blocos ideológicos (MUNANGA, 1988, p. 26). 
Há um apoio mútuo entre os negros, mas eles não querem se isolar do mundo, pois, além da busca pela identidade cultural e ação política, o outro objetivo fundamental da negritude, segundo Munanga (1988, p. 27), é o repúdio ao ódio. Pode-se afirmar, então, que "primordialmente, os negros apoiam-se no mundo inteiro [...]. A questão é contribuir para a construção de uma nova sociedade, onde todos os mortais poderão encontrar seu lugar" e ter em mente que

Cada sociedade tem a sua herança própria, isto é, a maneira de viver, de trabalhar, de pensar e a totalidade do que resulta dessas atividades (instituições, objetos, filosofia etc.), de modo que cada sociedade cria uma cultura, $e$ cada cultura repousa numa sociedade (Ibid., p. 32).

E todos esses aspectos se perfazem na linguagem, numa dada cenografia, que faz parte da cena de enunciação e é construída pelo próprio texto. Quando falamos em cenografia,

Não se trata simplesmente de uma moldura, de uma decoração, como se o discurso aparecesse no interior de um espaço já construído e independente dele, mas da enunciação que, por seu próprio desdobramento, institui a cena de enunciação que a legitima (MAINGUENEAU, 2010, p. 206).

E, também,

o ethos discursivo é coextensivo a toda enunciação: $o$ destinatário é necessariamente levado a construir uma 
representação do locutor, que este último tenta controlar, mais ou menos consciente e de maneira bastante variável, segundo os gêneros de discurso (Ibid., 2010, p. 79).

Maingueneau explica que há uma voz associada a um "corpo anunciante", e o discurso, "através da leitura ou da audição, faz com que o destinatário partilhe de certo movimento do corpo, em um processo de "incorporação" que implica certo "mundo ético", associado a comportamentos estereótipos" (Ibid., 2010, p. 80). O que não significa pensar que o sujeito corresponda a essa imagem. $\mathrm{Na}$ verdade, o sujeito, para nós, situa-se, constrói-se na incompletude em relação ao outro, num processo de alteridade, e na busca por uma identidade (BRANDÃO, 1996). É neste sentido, pois, que entendemos que a identidade do sujeito negro é, igualmente a de qualquer outro, uma construção que ocorre continuamente nas relações com outros sujeitos, com o mundo, com a história e consigo mesmo. O sujeito só se completa na relação com outro, embora busque, como estratégia monofonizante, criar um ethos de si.

Hall (2006, p. 3) coloca que

Para aqueles/as teóricos/as que acreditam que as identidades modernas estão entrando em colapso, o argumento se desenvolve da seguinte forma. Um tipo diferente de mudança estrutural está transformando as sociedades modernas no final do século XX [e início do século XXI]. Isso está fragmentando as paisagens culturais de classe, gênero, sexualidade, etnia, raça e nacionalidade, que, no passado, nos tinham fornecido sólidas localizações como indivíduos sociais. Estas transformações estão também mudando nossas identidades pessoais, abalando a ideia 
que temos de nós próprios como sujeitos integrados. Esta perda de um "sentido de si" estável é chamada, algumas vezes, de deslocamento ou descentração do sujeito. Esse duplo deslocamento - descentração dos indivíduos tanto de seu lugar no mundo social e cultural quanto de si mesmos - constitui uma "crise de identidade" para o indivíduo.

Hall ainda cita o crítico cultural Kobena Mercer para explicar a complexidade que envolve a crise de identidades: "a identidade somente se torna uma questão quando está em crise, quando algo que se supõe como fixo, coerente e estável é deslocado pela experiência da dúvida e da incerteza" (MERCER, 1990, p.43 apud HALL, 2006, p. 3-4). Outrossim, o discurso faz com que o enunciador circunscreva-se e delimite-se em determinada posição e confira, também, uma posição ao seu destinatário, e é essa ação de constituir-se num lugar e espaço determinado e fazê-lo também com o enunciador que legitima o dizer, ou seja, legitima a enunciação (CHARAUDEAU, 2008). Contudo, esse lugar "marcado" pelo discurso não é estável, ele é único e consoante à eventicidade única do enunciado, do Ser. É neste aspecto que Bakhtin (2011, p. 379) afirma: "para cada indivíduo, todas as palavras se dividem nas suas próprias palavras e nas do outro, mas as fronteiras entre elas podem confundir-se, e nessas fronteiras desenvolve-se uma tensa luta dialógica." Perspectiva dialógica de construção dos sujeitos, das sociedades, dos discursos; enfim, do mundo significado nas relações estabelecidas na sociedade.

Há de se considerar que os indivíduos estão descentrados de seu lugar social e de si mesmos, pelo fato de 
esses processos de mudança, tomados em conjunto, representam um processo de transformação tão fundamental e abrangente que somos compelidos a perguntar se não é a própria modernidade que está sendo transformada (HALL, 2006, p. 4).

A esse processo, Hall chama de mudança na modernidade tardia.

A concepção de sujeito da pós-modernidade (sujeito pós-moderno), nas palavras de Hall (2006), está fomentada no pensamento de que a identidade torna-se uma "celebração móvel". O sujeito pós-moderno é um sujeito em constante mudança, composto de várias identidades e assumindo várias identidades em diferentes momentos (HALL, 2008). Destarte, o sujeito pós-moderno não é um sujeito de essência, pronto, acabado, mas um sujeito que se constrói a cada momento de interação.

O sujeito pós-moderno, conceptualizado como não tendo uma identidade fixa, essencial ou permanente. A identidade torna-se uma "celebração móvel": formada e transformada continuamente em relação às formas pelas quais somos representados ou interpelados nos sistemas culturais que nos rodeiam (Hall, 1987). E definida historicamente, e não biologicamente. O sujeito assume identidades diferentes em diferentes momentos, identidades que não são unificadas ao redor de um "eu" coerente (HALL, 2006, p. 2).

Assim, reafirmamos nossa ideia de que, embora pertença a uma cultura, a uma sociedade, a um grupo histórica e socialmente 
situado, o sujeito negro constrói, atravessado por todas essas questões, sua identidade, que é, ao mesmo tempo, social e individual, pois ele, na relação com o outro, se constitui como sujeito e projeta, para este outro, durante a situação de encenação, um ethos "dito" e um ethos "discursivo", que ora coincidirão, ora não (MAINGUENEAU, 2010).

No próximo ponto, falaremos um pouco mais sobre o conceito de negritude e a construção do ethos nas amostras que separamos.

\section{Cenografia, hipermídia e negritude: espaços de construção de identidade}

Maingueneau (2015) usa o termo cena de enunciação por acreditar que os conceitos de "situação de comunicação" e "situação de enunciação" não dão conta do processo de interação discursiva que se constrói numa dada enunciação, nem das circunstâncias sociais de produção do discurso que a possibilitam e, por isso, o autor usa o termo cena por este apresentar, ao mesmo tempo, um quadro e um processo: ela é

O espaço bem delimitado no qual são apresentadas as peças [...], e a sequência das ações verbais e não verbais que habitam esse espaço [...]. De fato, o discurso pressupõe certo quadro, definido pelas restrições do gênero, mas deve também gerir esse quadro pela encenação de sua enunciação (MAINGUENEAU, 2015, p. 117).

É partir do conceito de cena de enunciação que faremos nossas considerações. Tal cena faz interagir, conforme o autor, três 
outras cenas: a cena englobante, a cena genérica e a cenografia. Não nos interessa, para este estudo, a discussão sobre a cena englobante, pois ela tem mais a ver com os "tipos de discurso"; tão pouco nos aprofundaremos sobre a cena genérica, porque esta, embora funcione como norma e expectativa do comportamento discursivo do sujeito locutor, não é suficiente para dar conta, conforme Mainguenau (2015), da singularidade de um texto, posto que "enunciar não é apenas ativar as normas de instituição de fala prévia; é construir sobre essa base uma encenação singular da enunciação: uma cenografia" (p. 122, grifo do autor). Logo, no que diz respeito à enunciação das amostras de análises que traremos, nos interessa o conceito de cenografia, que "se apoia na ideia de que o enunciador, por meio da enunciação, organiza a situação a partir da qual pretende enunciar" (Ibid. p. 123). A cenografia legitima o discurso, principalmente porque o locutor projeta um ethos dito que coincidirá ou não com um ethos discursivo. Ela se desenvolve à medida que o locutor controle esse desenvolvimento. É o que veremos mais adiante, quando observarmos a construção do ethos de um sujeito que se identifica como negro e que sofre as consequências de um racismo estrutural.

Antes, é preciso entender que, enquanto conceito e movimento ideológico, negritude é uma discussão relativamente recente, que tem, por um lado, uma concepção mítica, pautada na descoberta do passado e explicação do mundo, especificamente da África, anterior à intervenção do ocidente; e uma concepção ideológica, que trataria sobre um modo mais agressivo de negritude em relação ao branco, como resposta a diferentes situações passadas pelo negro em detrimento de sua raça/cor, sejam elas históricas, psicoemocionais, de humilhação, entre outras (MUNANGA, 1988). De todo modo, as duas concepções, cada uma com suas lacunas e contribuições, buscam uma reparação histórica para a população negra. 
Munanga (1988) também discorre sobre o caráter biológico ou racial e psicológico da negritude, fala sobre o conceito sociocultural de classe e a definição cultural do termo. Para o autor, no primeiro caso, negritude é a consciência de pertencimento à raça negra; negritude teria a ver, então, com tudo que tange à raça negra. Sobre o aspecto psicológico, Munanga (ibid. p. 29) destaca que "a negritude seria, no caso, o conjunto de traços característicos do negro no que se refere a comportamento, capacidade de emoção, personalidade e alma”. Já numa definição cultural, o negro se afirma pela valorização de sua cultura. Vale a pena destacar a seguinte fala do autor:

A negritude nasce de um sentimento de frustração dos intelectuais negros por não terem encontrado no humanismo ocidental todas as dimensões de sua personalidade. Neste sentido, ela é uma reação, uma defesa do perfil cultural do negro. Representa um protesto contra a atitude do europeu em querer ignorar outra realidade que não a dele, uma recusa da assimilação colonial, uma rejeição política, um conjunto de valores do mundo negro que devem ser reencontrados, defendidos e mesmo repensados. Desalienação autêntica (MUNANGA, 1988, p. 31).

Embora Munanga fale de um momento anterior ao que estamos vivendo, suas considerações são completamente aplicáveis ao que acontece na sociedade atual. A população negra ainda é a que mais sofre com as mazelas e desigualdades sociais ${ }^{3}$, a comunidade carcerária é composta, em sua maioria, por pessoas negras ${ }^{4}$, a ex3 Conf.: https:/www.ibge.gov.br/estatisticas/sociais/populacao/25844-desigualdades-sociais-por-cor-ou-raca.html? =\&t=sobre.

4 Conf.: https://g1.globo.com/sp/sao-paulo/noticia/2020/10/19/em-15- 
pectativa de vida de uma pessoa negra é menor do que a de uma branca $^{5}$, dentre tantas outras situações.

Pensar em como as identidades da população negra se constroem na atualidade deve levar em conta que essa população faz parte de sociedades histórica, cultural e ideologicamente diversificadas e que estão a todo instante se significando e significando o mundo. Não obstante, é preciso ter cuidado para não tornar o sujeito negro uma coisa "única", porque não o é. Entender as sociedades contemporâneas constituídas em relação umas com as outras é ter claro que os processos de construção de identidades são complexos, por certo assimétricos e de difícil contorno. Giddens (2007, p. 19) afirma que

Vivemos em um mundo de transformações, que afetam quase tudo o que fazemos. Para melhor ou para pior, estamos a ser empurrados para uma ordem global que ainda não compreendemos na sua totalidade, mas cujos efeitos já se fazem sentir em nós.

As transformações as quais as sociedades atuais passam são próprias de suas identidades, as constitui (HALL, 2006). Essas transformações, necessariamente, afetam as relações entre as pessoas e contribuem na construção de suas identidades. Repetimos: o sujeito é construído em sua relação com o outro. As redes sociais, nesse sentido, se "[...] constituem em ambientes virtuais programados muito justamente para promover o diálogo no seu mais alto grau de intensificação", e sua linguagem “[...] tanto nos sites de

anos-proporcao-de-negros-nas-prisoes-aumenta-14percent-ja-a-debrancos-diminui-19percent-mostra-anuario-de-seguranca-publica. ghtml.

5 Conf.: https://www.uol.com.br/vivabem/reportagens-especiais/saude-da-populacao-negra/\#page1. 
relacionamento quanto na ação de navegar pelas redes informacionais, é inteiramente nova, trazendo com ela um gênero discursivo eminentemente híbrido, hipermidiático" (SANTAELLA, 2014, p. 210-211). Neste novo espaço de interação, a esfera digital, o discurso se faz presente através dessa [nova] linguagem própria desse espaço, a hipermídia, que mescla o hipertexto com a multimídia e é entendida como

a linguagem por excelência das redes e que está longe de se limitar a programas e produtos. Ela é, na realidade, uma nova configuração das linguagens humanas, assim como o livro, o jornal, o cinema e o vídeo foram e continuam sendo configurações de linguagens com características próprias. [...] as plataformas atuais, como os blogs, as redes sociais - e mesmo as wikis - permitem que o antigo receptor se converta em produtor e divulgador de suas próprias mensagens, traço fundamental desse novo tipo de gênero discursivo que, além de híbrido, coloca nas mãos do usuário o destino de suas viagens e perambulações pelas redes, suas trocas e compartilhamentos no diálogo com o outro (ibid., p. 216).

E, como toda linguagem, a hipermídia não é algo acabado, pronto para ser utilizado, mas "uma atividade humana que se desdobra no teatro da vida social e cuja encenação resulta de vários componentes, cada um exigindo um 'savoir-faire' [...]" (CHARAUDEAU, 2008, p. 7). A hipermídia também é um ambiente onde a cenografia acontece, pois esta não se trata, simplesmente, de um cenário: a cenografia "legitima um enunciado que, em troca, deve legitimá-la, deve estabelecer que essa cenografia da qual a fala vem é precisamente a cenografia requerida para enunciar como con- 
vém num ou noutro gênero de discurso" (MAINGUENEAU, 2015, p. 123). É nesse sentido que observaremos em nossas amostras de análises a construção do ethos de identidade negra dentro de uma dada cenografia, considerando a seguinte fala de Munanga (1988, p. 6) sobre negritude:

O termo negritude não permaneceu estático. [...]. Enquanto movimento, a negritude desempenhou historicamente seu papel emancipador, traduzido pelas independências africanas e estendeu-se como libertação para todos os negros na diáspora, ainda vítimas do racismo branco, por exemplo, nas Américas (MUNANGA, 1988, p. 6).

Negritude é também a retomada do negro de si a suas origens como forma de resistir ao embranquecimento, aceitação de sua herança sociocultural e uma reação legítima do negro contra a atitude agressiva branca (ibid., 1988; 2000). Este movimento também acontece na atualidade, principalmente nas redes sociais.

$\mathrm{Na}$ hipermídia, diferentes recursos semiótico-linguísticos aparecem concomitantemente; linguagem verbal, sons, imagens, caracteres e narrativas próprias do ambiente virtual, mas que invadem o plano físico-real, como as hashtags. A hipermídia se constrói no ciberespaço e está altamente presente e influente na sociedade, permite a interação entre diferentes sujeitos de lugares diversos, difunde e reproduz ideias. (SANTAELLA, 2014). Nessas interações, discursos e identidades são construídos.

Assim sendo, a identidade é a diferença em relação ao outro, mas ela não é estanque, durável e homogênea, mas está em constante transformação a cada troca, cada experiência, cada interação: 
Quanto mais forte é a consciência do outro, mais fortemente se constrói a sua própria consciência identitária. É o que se chama de princípio de alteridade. Esta relação ao outro se institui através de trocas que fazem com que cada um dos parceiros se reconheça semelhante e diferente do outro. Semelhante: na medida em que, para que uma relação exista entre seres humanos, é necessário que estes compartilhem, ainda que parcialmente, as mesmas motivações, as mesmas finalidades, as mesmas intenções. Diferente: na medida em que cada um desempenha papéis que lhe são próprios e que, em sua singularidade, cada um tem finalidades e intenções que são distintas das do outro (CHARAUDEAU, 2009, p.1).

Percebamos agora este movimento duplo de reconhecer-se como indivíduo e de pertencente a um grupo, pela projeção de um ethos de identidade de pessoa negra. A consciência reivindicativa de que fala Munanga (2000) pode ser percebida numa postagem recente da cantora Ludmilla em seu perfil na rede social Twitter. A cantora recusou, via postagem em rede social, participar da premiação do evento "Prêmio Multishow 2021", por não ter sido indicada, mais uma vez, para as principais categorias do prêmio, como a de melhor cantora do ano de 2021, mesmo sendo uma das artistas mais ouvidas e vistas do país: 


\section{LUDMILLA 9}

Tujomitis

Sou a primeira cantora negra da América Latina a acumular 1 bilhão de streams só no Spotify, hoje sảo mais de 1.5 bilhäo de plays nas plataformas. Meus clipes somam 2.5 bilhōes de views, Rainha da Favela ficou meses entre as músicas mais tocadas. São os números que falam!

10.20 - 19 oul 21 . I wilsm lar IPhiam

5.096 Relwmen 2.643 Twmete cam comeniase

\subsection{K Curtidas}
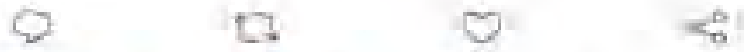

\section{LUDMILLA $\mathrm{C}$ el iadnilia $19 \mathrm{mal}$}

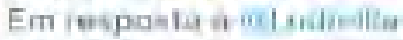

Só esse ano lnncai o numanice ad vivo. projeta que impactou a cultura brasileira o revolucionou o mercado do pagode de um jeito jamais visto, por ser ume mulher a flente do projeto, projeto que garantiu o video murical solo mais visto de 2021 por ume cantore pop brasileira..

Figura 01: Primeiro tuíte de Ludmilla, em 19 de outubro de 2021, após a divulgação dos nomes dos indicados ao "Prêmio Multishow Melhores do Ano de 2021". 

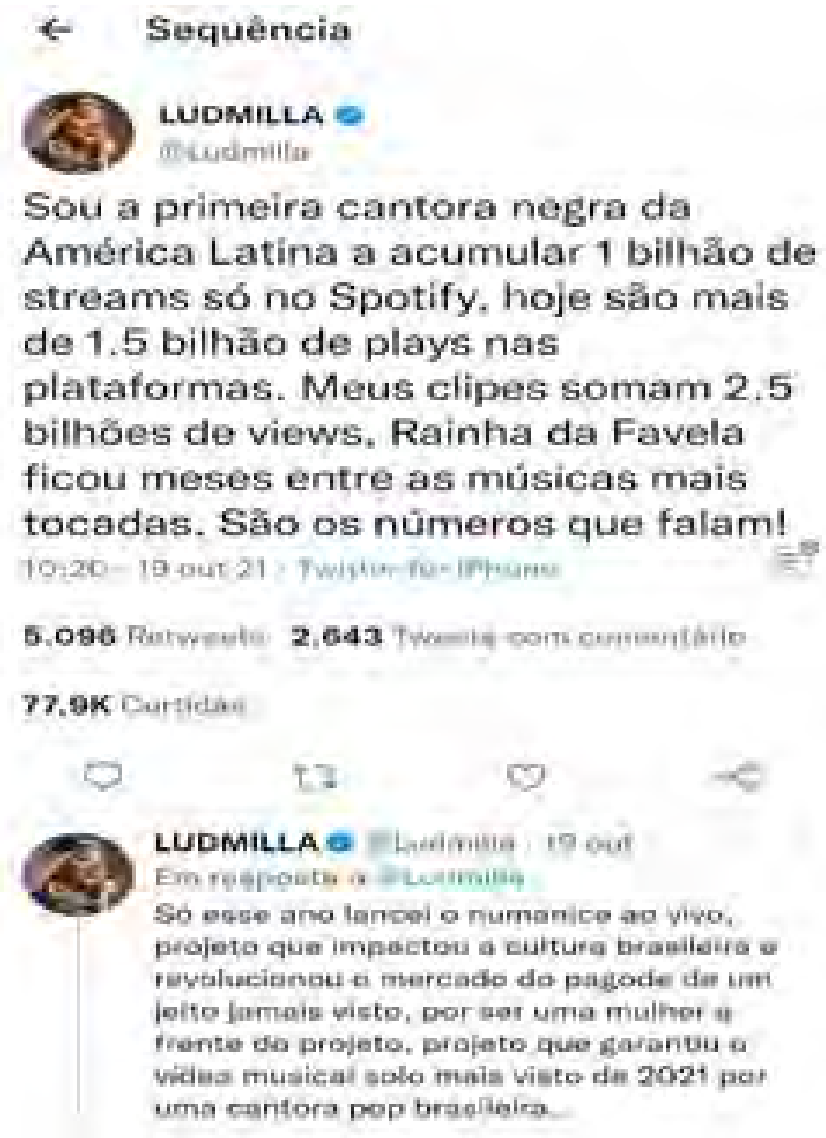

Figura 02: segundo tuíte de Ludmilla em referência à sua participação na festa da premiação.

$\mathrm{Na}$ cena enunciativa, o gênero de discurso usado pela cantora foi o tuíte, tipo de postagem feita na rede social Twitter, uma das plataformas mais usadas da hipermídia. Ancorando-nos nas ideias de Maingueneau (2010), afirmamos que a escolha dessa cena foi plena de sentido, pois teve maior alcance do que teria uma nota 
à imprensa ou mesmo um e-mail oficial ao grupo organizador do evento. A postagem no Twitter teve um alcance maior e mais global e, por isso, poderíamos pensar, que essa cenografia pode se caracterizar como "exógena" (MAINGUENEAU, 2015), pois usa funções próprias de outros gêneros no gênero tuíte e perfila um ethos de um sujeito consciente dos impactos que esse movimento trará (MAINGUENAU, 2010). A esse tipo de performance enunciativa na plataforma dá-se o nome de thread'.

Ao longo de sua narrativa, que é desenvolvida numa sequência de postagens que procuram justificar a decisão de não participar da festa de premiação, a cantora projeta um ethos "dito" que, ao final, coincidirá com o ethos discursivo percebido no todo da cena enunciativa, e constrói uma imagem de um sujeito que foi, como noutros momentos, injustiçado; injustiça essa que o sujeito faz crer se dever ao racismo estrutural que existe na sociedade, inclusive na música e no entretenimento. Essa imagem de si, de um sujeito indignado com a falta de representatividade, um sujeito quase invisível aos olhos de uma grande rede de comunicação, é construída, também, através de dados apresentados pelo próprio sujeito, a cantora:

6 Thread no Twitter é um conjunto de tuítes numerados e vinculados uns aos outros para usuários contarem histórias, compartilharem informações e iniciarem debates com os seus seguidores. Conf. Em: https://www.techtudo.com.br/listas/2021/09/o-que-e-thread-no-twitter-veja-dicas-para-fazer-uma-sequencia.ghtml. 


\section{$\leftarrow$ Sequência}

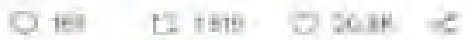

LUDMILLA GLudmata 18 wis

Dé̈́a de Crida_Pra Te Machaces, Bato

Sames. Ape toot, o Lut Session mentàn nem se talac ta na beca do povo. Deode quando sarhei a primeirs wez e impocted todo o cistama per ter a primeira cantora nuge a set inditada o a ventive essa calogor ia ver $2 e$ arion de prômin.

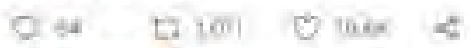

LUDMHLA D Nudmilin y 19 ain uma representante das mirsorias. uma carviora noya. bicsexual, funkeira. perifbrica, nunca mais ful incleoda ma cateroria "Cantora de Ano". Infeliznarise oseca of a forma que o sistema to boicutal Mesmo eu sundo indicada en outras categorias da premiaçbo-
इ $x=1$
D.7 4 ak
$19,4 k$

\section{LUDMILLA 8 aLudmalla - 7 है on}

of nitida n falta de reconhecimento $e$ entendimento das (poucas) premiaçós que tamos aquil no Elrasil, Assim corrou uu, vàrios artistus de vârias segmentos e handeims. que mereciam ser indicados bu serem reconthucidos da mesma farma que entregam conteiddas parn sesis póblicos.

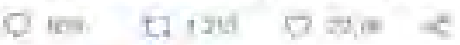

\section{LUDMILAO QLUdMIlla i IS gur}

e *stî̀o na mesina siloaçầ.

Ventib por meio desse tweet avisar a todos 4

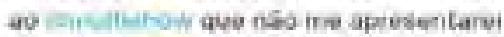
mais no petimio esce uno, Obrigada pela capvilte, mas onde n\$o sou bem vinca perefire

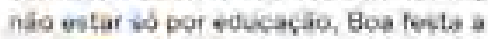
todos $\left.{ }^{2}\right)$ 


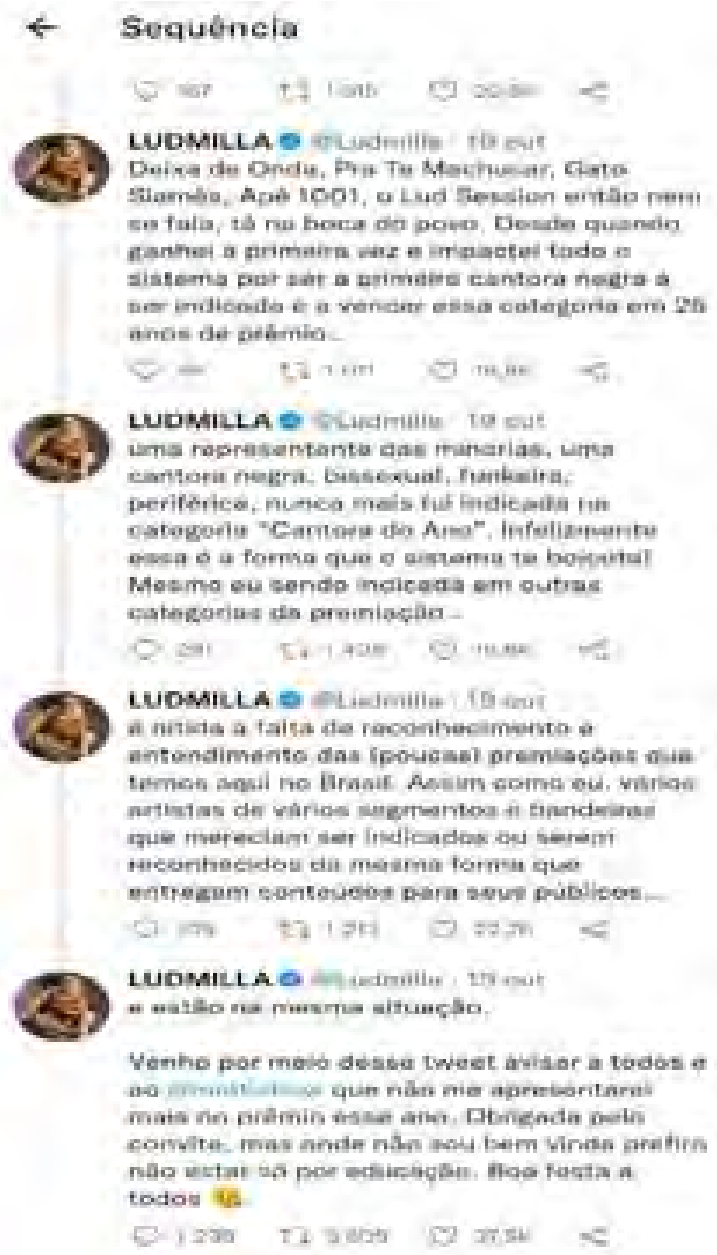

Figura 03: Postagens sequenciais (thread) feitas pela cantora Ludmilla, em 19 de outubro de 2021, após a divulgação dos nomes dos indicados ao prêmio de "Prêmio Multishow 2021", recusando o convite para participar do evento. 
O ethos projetado nas postagens de Ludmilla também evidencia um sujeito que procura falar em nome de outros artistas que, assim como ela, mereciam ser indicados, mas não foram. Todo esse discurso de revolta, de queixa e protesto é construído no fio narrativo da rede social, mas reflete diretamente em outros espaços, como em programas de fofoca e sites de notícias, além de outras redes sociais, o que comprova que "as transformações por que tem passado a cultura digital e a aceleração dessas transformações são vertiginosas, especialmente devido à emergência dos dispositivos móveis" (SANTAELLA, 2014, p. 277). Ao passo que

[...] a lógica das redes, potencializada pelo alto nível de conexão da sociedade e especialmente a partir da fusão da telefonia móvel com as tecnologias de rede, leva a que cada indivíduo esteja não somente conectado, mas, literalmente, seja um potencial nó da trama, transitando por uma fronteira entre o humano e o tecnológico (FRANCO; TEIXEIRA, 2007, p. 45).

O primeiro post $^{7}$ relacionado ao assunto teve, até dia 09 de novembro de 2021, mais de setenta e sete mil curtidas e mais de duas mil repostagens ${ }^{\star 8}$. É neste ambiente de hipermídia que Ludmilla constrói seu discurso e projeta um ethos de um sujeito que quer ser reconhecido em suas qualidades artísticas individuais e que conhece os motivos pelos quais não foi indicada. Essa postura da cantora revela, através da linguagem e de um gênero próprio do ambiente digital, uma consciência política reivindicativa enquanto vítima do racismo nas sociedades contemporâneas, que entendemos ser, a partir de Munanga (2000), um exemplo de uma nova

7 Nas redes sociais, equivale à postagem, publicação.

8 Repostagem ou repost: quando se republica a postagem (post) de alguém. 
forma de discriminação racial: construída com base nas diferenças culturais e identitárias. Ao finalizar sua sequência de postagens com "Obrigada pelo convite, mas onde não sou bem-vinda prefiro não estar só por educação", a cantora exemplifica que os negros reivindicam o reconhecimento público de suas identidades para a construção de uma nova imagem positiva, que lhe devolva a autoestima (MUNUNGA, 2000).

Esse exemplo nos mostra que as tecnologias exercem papel importante nestas sociedades contemporâneas, fazem parte da dinâmica social (MARCON; TEIXEIRA, 2011); sobretudo, "todos os produtos da criatividade humana nascem na e para a sociedade humana" (BAKHTIN/VOLOCHÍNOV, 1976, p. 2) e, nas sociedades contemporâneas, "trata-se de interatividade com a mídia e de interatividade com outros usuários remotos ou presentes no mesmo espaço físico [...] (ROJO, 2017, p. 15)”.

A mesma reivindicação é percebida no videoclipe e letra da música "AmarElo", interpretada por Emicida, Majur e Pabllo Vittar, com Sample do refrão da música "Sujeito de sorte" de Belchior". O videoclipe começa com um desabafo de um rapaz a quem chama de tio. O rapaz fala que não aguenta mais a pressão e as dificuldades que da vida, e segue falando de alguns atritos e pensamentos suicidas; o jogo com as palavras amar e elo é além de semiótica, pois fala da cor de alerta, o amarelo, visual e discursiva: visual pois destaca, em maiúscula, o "E", de elo, para que o espectador visualize as duas palavras justapostas; e discursiva porque trata-se de um projeto de dizer com a semântica das palavras amar, elo e amarelo. O ethos começa a ser projetado de modo dito e discursivo desde o título. Analisemos alguns trechos da música e duas imagens capturadas do videoclipe:

9 Disponível em: https://www.youtube.com/watch?v=PTDgP3BDPIU. 


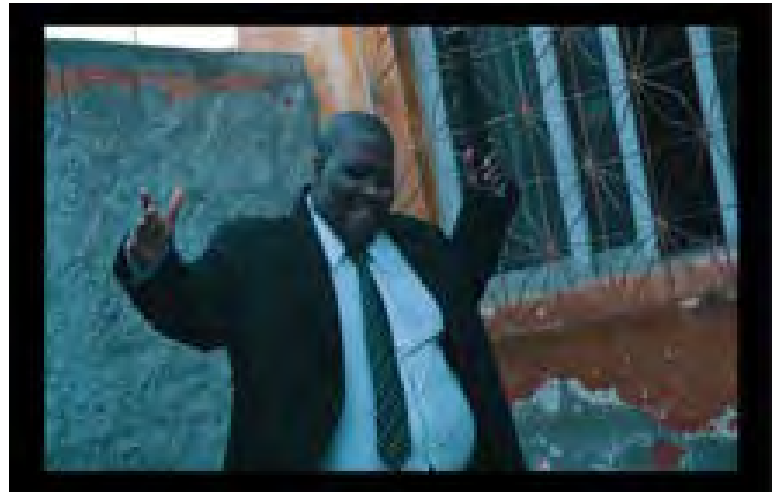

Figura 04: Imagem capturada em 07:50 do videoclipe "AmarElo".

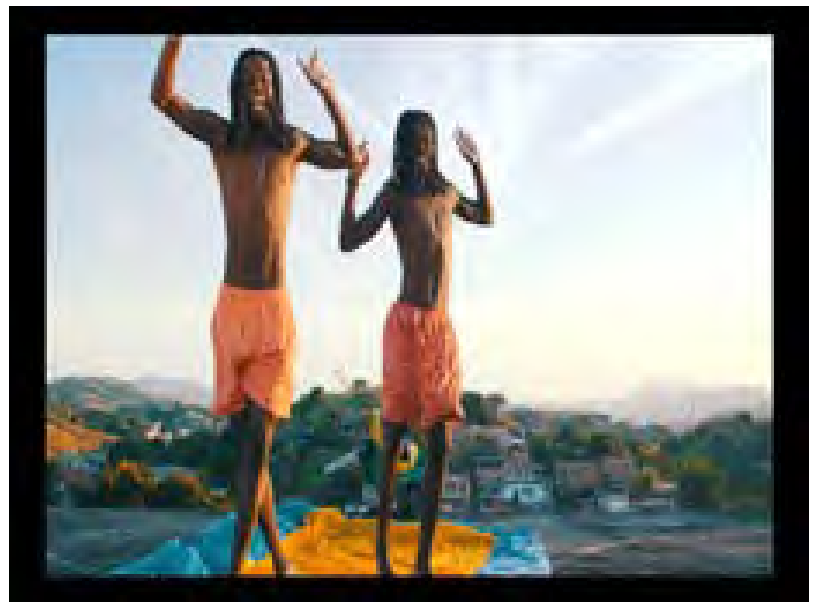

Figura 05: Imagem capturada em 08:53 do videoclipe "AmarElo". 
Trecho da música:

$[\ldots]$

Eu sonho mais alto que drones

Combustível do meu tipo? A fome

Pra arregaçar como um ciclone (entendeu?)

Pra que amanhã não seja só um ontem

Com um novo nome

O abutre ronda, ansioso pela queda (sem sorte)

Findo mágoa, mano, sou mais que essa merda (bem mais)

Corpo, mente, alma, um, tipo Ayurveda

Estilo água, eu corro no meio das pedra

Na trama, tudo os drama turvo, eu sou um dramaturgo

Conclama a se afastar da lama, enquanto inflama o mundo

Sem melodrama, busco grana, isso é hosana em curso

Capulanas, catanas, buscar nirvana é o recurso

É um mundo cão pra nóiz, perder não é opção, certo?

De onde o vento faz a curva, brota o papo reto

Num deixo quieto, num tem como deixar quieto

A meta é deixar sem chão, quem riu de nóiz sem teto

[...]

Permita que eu fale, não as minhas cicatrizes

Elas são coadjuvantes, não, melhor, figurantes, que nem devia tá aqui

Permita que eu fale, não as minhas cicatrizes

Tanta dor rouba nossa voz, sabe o que resta de nóiz?

Alvos passeando por aí

Permita que eu fale, não as minhas cicatrizes 
Se isso é sobre vivência, me resumir a sobrevivência É roubar o pouco de bom que vivi Por fim, permita que eu fale, não as minhas cicatrizes Achar que essas mazelas me definem, é o pior dos crimes É dar o troféu pro nosso algoz e fazer nóiz sumir. [...]

Para além das questões de heterogeneidade mostrada e constitutiva, importa-nos aqui observar a construção da identidade do sujeito que se perfaz na canção, através de um ethos de um sujeito combatente, consciente e, principalmente, único, que não se "resume às próprias cicatrizes", como em "[...] me resumir à sobrevivência é roubar o pouco de bom que vivi" e "permita que eu fale, não as minhas cicatrizes/Achar que essas mazelas me definem, é o pior dos crimes/É dar o troféu pro nosso algoz e fazer nóiz ${ }^{*}$ sumir." Nestes e noutros versos, é possível perceber que "a crise desperta no negro um desejo de afirmação cada vez maior. Ultrapassando os limites da literatura, a negritude aspira ao poder, anima a ação política e a luta pela independência” (MUNANGA, 1988, p. 26).

O ethos, que começa a ser projetado com um depoimento aparentemente suicida em discurso direto, constrói, ao final do vídeo e da letra da música, um sujeito consciente das desigualdades sociais, geradas principalmente pelo racismo presente na sociedade, mas é, igualmente, um sujeito que rompe com os estereótipos: ele não quer sobreviver, se conformar, mas quer viver de suas próprias escolhas, na dança, na música, nos estudos. Ele sonha "mais alto que drones". As imagens capturadas do clipe nos mostram, por exemplo, um rapaz feliz por ter conseguido seu diploma e dois outros também felizes, aparentemente, por estarem dançando. A identidade desse sujeito evidencia, conforme Maingueneau (2010), que o ethos é uma maneira de ser. 


\section{Considerações finais para diálogos futuros}

É por saber e conhecer o racismo estrutural presente e evidente em nossa sociedade que nos propusemos a discutir a questão da construção da identidade do povo preto na sociedade brasileira atual, ao mostrar que essa população, assim como as demais, é diversa, multifacetada e cultural e discursivamente heterogênea, embora apresente um ponto em comum a todos os negros: a busca por uma sociedade mais igualitária, na qual o racismo seja, de uma vez por todas, superado. Evidenciamos que é por ver e sentir esse racismo latente, que o sujeito negro, nas amostras que trouxemos, não aceita a imagem e lugar dado a ele na sociedade, buscando através da linguagem e de seu discurso, fazer-se ouvido.

A ubiquidade das palavras negro e preto reside, para nós, na desintoxicação semântica dos termos e na compreensão de que não há lugares onde o negro deva estar; ele pode estar em todos os lugares. Nesse sentido, entendemos que a hipermídia, enquanto linguagem e suporte de discurso, traz grandes impactos para as identidades culturais e sociais dos indivíduos, pois é, como outros espaços e circunstâncias de produção de discurso, lugar de produção de cenografias. Por último, ratificamos nossa fala de que o sujeito negro é, como tal, é histórico, social, cultural e, também, único. Terminamos, assim, com a seguinte fala de Marxismo e Filosofia da Linguagem (2009, p. 40): a palavra é o modo mais puro e sensível de relação social. 


\section{Referências}

BAKHTIN, B. Estética da criação verbal. $6^{\text {a }}$ Ed. São Paulo: Martins Fontes, 2011.

BAKHTIN, B. Para uma filosofia do Ato Responsável. São Carlos: Pedro \& João, 2010.

BAKHTIN, B. Marxismo e Filosofia da Linguagem. 13 ed. São Paulo: HUCITEC, 2009.

BRANDÃO, H. N. Introdução à análise do discurso. Campinas: Editora da Unicamp, 1996.

CHARAUDEAU, P. Linguagem e discurso: modos de organização. São Paulo: Contexto, 2013.

CHARAUDEAU, P. Discurso das Mídias. São Paulo: Contexto, 2013.

CHARAUDEAU, P. Identidade social e identidade discursiva: o fundamento da competência comunicacional. In: PIETROLUONGO, Márcia. (Org.) O trabalho da tradução. Rio de Janeiro : Contra Capa, 2009, p. 309326.

GIDDENS, Anthony. O mundo na era da globalização. Queluz de Baixo/ Barcarena: Presencial, 2007. P. 19 - 30.

HALL, S. A identidade cultural na pós-modernidade. Rio de Janeiro. DP\&A, 2006.

MAINGUENEAU, Dominique. Discurso e análise do discurso. $1^{\text {a }}$ ed. Tradução Sírio Possenti. São Paulo: Parábola Editorial, 2015.

MAINGUENEAU, Dominique. Doze conceitos em Análise do discurso. São Paulo: Parábola, 2010.

MAINGUENEAU, Dominique. A Análise do Discurso e suas Fronteiras. Matraga, [S.I], 2007. V. 14, n 20, p. 13-37.

MAINGUENEAU, Dominique. Gêneses do Discurso. Curitiba: Criar, 2005.

MUNANGA, Kabengele. Uma abordagem conceitual das noções de raça, racismo, identidade e etnia. In: BRANDÃO, André A. B. Programa de Educação sobre o negro na sociedade brasileira (Orgs). Niterói: EdUFF, 2000. 
114 Negritude(s) E identidade(s) NA Hipermídia

MUNANGA, Kabengele. Negritude: usos e sentidos. $2^{\text {a }}$ ed. São Paulo: Ática. Série Princípios, 1988.

SANTAELLA, L. Gêneros discursivos híbridos na era da hipermídia. Bakhtiniana: São Paulo, 9 (2): 206-216, Ago./Dez. 2014.

SPINELLO, S.; TEIXEIRA, A. C. Medindo a interatividade em um ambiente de autoria hipermídia: qualificando processos de inclusão digital. Renote - Revista Novas Tecnologias na Educação, v. 1, p. 1-10, 2008. 